\title{
DCD lungs: is it all the same?
}

\author{
Elena Sandoval ${ }^{1}$, Alejandro Fernández-Cisneros ${ }^{1}$, Marc Boada $^{2}$ \\ ${ }^{1}$ Department of Cardiovascular Surgery, ICCV. Hospital Clínic, Barcelona, Spain; ${ }^{2}$ Department of Thoracic Surgery, ICR. Hospital Clínic, \\ Barcelona, Spain \\ Correspondence to: Elena Sandoval, MD, FEBCTS. Department of Cardiovascular Surgery, ICCV. Hospital Clínic, C/Villarroel 170 Esc 15 th floor, \\ 08036 Barcelona, Spain. Email: esandova@clinic.cat.
}

Submitted Sep 02, 2019. Accepted for publication Nov 15, 2019.

doi: 10.21037/acs.2019.11.07

View this article at: http://dx.doi.org/10.21037/acs.2019.11.07

Lung transplantation is the gold-standard treatment for end-stage lung disease. Presently, the paucity of available donors has led to a yearly increase of the waiting list that has exponentially exceeded the actual transplant rate (1). This imbalance has led to the usage of the so-called "extended donors", lobar transplant or a renewed interest in using donors after circulatory death, or "DCD donors" (2).

In donation after circulatory death, there are two completely different scenarios; donors can be "controlled" or "uncontrolled". In "controlled DCD" (cDCD), the donation takes place after withdrawal of care in an ICU environment when neurogenic lung edema is not present or not fully established. On the other hand, "uncontrolled donors" (uDCD) are those whom after unsuccessful reanimation are considered potential donors by the emergency teams and brought to the hospital to be declared clinically and legally dead. Differentiating uDCD from cDCD is mandatory before analyzing outcomes, as ischemic times and donor assessment are completely different.

Spanish groups have shown that the key to success with uDCD is having an already established system (3). Initial results were inferior to brain death donor (DBD) lungs with a significantly higher incidence of primary graft failure (PGD), probably due to difficulties in the evaluation of the organs (4). With the introduction of ex-vivo lung perfusion systems (EVLP) (5), reliable organ evaluation is possible and has led to improved outcomes compared to DBD (6). Recently published series for cDCD's, report excellent short-term outcomes, with 1-year survival of $89 \%$ and 5 -year survival of $61 \%$, similar to DBD with 1- and 5-year survival of $88 \%$ and $61 \%$, respectively (7).

We think rather than focusing on the short-term results, we should explore the long-term results and data on
Chronic Lung Allograft Dysfunction (CLAD). Different results have been published regarding this issue $(4,8)$. We consider that key elements determining outcomes that have not been well defined are the effect of warm ischemia and agonal time (i.e., time from systemic blood pressure below $50 \mathrm{mmHg}$ to pneumoplegia administration) (9). Initial reports limited it to 60 minutes; however, further investigations showed that lungs are more resistant to ischemia while ventilated, due to oxygen diffusion through the alveolar membrane (10). Differences in warm ischemic time set a certain limitation for outcome comparison (9).

What about ex-vivo lung perfusion (EVLP)? Doesn't it go together with DCD lungs? Actually, not always. EVLP allows for the lungs to be perfused and ventilated out of the body (11). EVLP also allows for further functional evaluation and extended transport time; however, for cDCD cases, it is not clear if it is necessary to use EVLP, as the lung only suffers the period of functional warm ischemia and a short period of non-ventilation. On the other hand, we consider that EVLP should be mandatory in all cases of uDCD, not only for functionality assessment, but for organ recovery; both experimental and clinical studies have showed improved results with $\mathrm{UDCD}$ and $\operatorname{EVLP}(6,12)$.

To conclude, DCDs are proven to be a safe and reliable source of organs for transplantation. Mainly, cDCDs have significantly increased the donor pool in several lung transplant programs, whereas the use of uDCDs has not provided the same increase because of logistic, legal and ethical reasons. Nonetheless, we strongly believe uDCD will become an important source of lungs in the future. There are still some gaps in knowledge and technical difficulties that limit its spread worldwide and these must be investigated. 


\section{Acknowledgments}

We would like to make a special mention to our mentors for their support.

\section{Footnote}

Conflicts of Interest: The authors have no conflicts of interest to declare.

\section{References}

1. Chambers DC, Yusen RD, Cherikh WS, et al. The Registry of the International Society for Heart and Lung Transplantation: Thirty-fourth Adult Lung And HeartLung Transplantation Report-2017; Focus Theme: Allograft ischemic time. J Heart Lung Transplant 2017;36:1047-59.

2. Egan TM, Lambert CJ Jr, Reddick R, et al. A strategy to increase the donor pool: use of cadaver lungs for transplantation. Ann Thorac Surg 1991;52:1113-20; discussion 1120-1.

3. Miñambres E, Rubio JJ, Coll E, et al. Donation after circulatory death and its expansion in Spain. Curr Opin Organ Transplant 2018;23:120-9.

4. de Antonio DG, Marcos R, Laporta R, et al. Results of clinical lung transplant from uncontrolled non-heartbeating donors. J Heart Lung Transplant 2007;26:529-34.

5. Cypel M, Yeung JC, Liu M, et al. Normothermic ex vivo lung perfusion in clinical lung transplantation. $\mathrm{N}$ Engl J

Cite this article as: Sandoval E, Fernández-Cisneros A, Boada M. DCD lungs: is it all the same? Ann Cardiothorac Surg 2020;9(1):54-55. doi: 10.21037/acs.2019.11.07
Med 2011;364:1431-40.

6. Suberviola B, Mons R, Ballesteros MA, et al. Excellent long-term outcome with lungs obtained from uncontrolled donation after circulatory death. Am J Transplant 2019;19:1195-201.

7. Cypel M, Levvey B, Van Raemdonck D, et al. International Society for Heart and Lung Transplantation Donation After Circulatory Death Registry Report. J Heart Lung Transplant 2015;34:1278-82.

8. Sabashnikov A, Patil NP, Popov AF, et al. Long-term results after lung transplantation using organs from circulatory death donors: a propensity score-matched analysis†. Eur J Cardiothorac Surg 2016;49:46-53.

9. Levvey B, Keshavjee S, Cypel M, et al. Influence of lung donor agonal and warm ischemic times on early mortality: Analyses from the ISHLT DCD Lung Transplant Registry. J Heart Lung Transplant 2019;38:26-34.

10. Ruttens D, Martens A, Ordies S, et al. Short- and Longterm Outcomes After Lung Transplantation From Circulatory-Dead Donors: A Single-Center Experience. Transplantation 2017;101:2691-4.

11. Valenza F, Rosso L, Coppola S, et al. Ex vivo lung perfusion to improve donor lung function and increase the number of organs available for transplantation. Transpl Int 2014;27:553-61.

12. Charles EJ, Mehaffey JH, Sharma AK, et al. Lungs donated after circulatory death and prolonged warm ischemia are transplanted successfully after enhanced ex vivo lung perfusion using adenosine A2B receptor antagonism. J Thorac Cardiovasc Surg 2017;154:1811-20. 